\title{
Arctic sea ice seasonal-to-decadal variability and long-term change
}

doi: 10.22498/pages.25.1.14

\section{Dirk Notz}

\author{
Max Planck Institute for Meteorology, Hamburg, Germany
}

\section{Introduction}

The large-scale loss of Arctic sea ice in recent decades is one of the most prominent indicators of the ongoing global climate change. This derives from three main reasons. First, climate change is amplified in the Arctic ("Arctic amplification", e.g. Pithan et al. (2013)), so consequences of changes in the global-mean climate are more readily observed at high latitudes compared to middle and lower latitudes. Second, while many observables change gradually with global mean climate, Arctic sea ice is among those observables that might eventually cross a binary threshold from "existing" to "non-existing", which amplifies the perception of the underlying gradual trend. And third, as a consequence, changes in "Arctic sea ice coverage" are easier to grasp and communicate to a general public than changes in more abstract metrics such as "global mean temperature".

The observed changes in Arctic sea ice are not only a clear local indicator of large-scale climate change; the ice loss also has a number of sometimes far-reaching worldwide consequences. These include physical phenomena such as the possible impact on mid-latitude weather system or the disruption of the oceanic uptake of $\mathrm{CO}_{2}$, but also societal consequences such as the opening of new shipping routes or the necessary changes in the lifelihood of the Arctic indigenous population.

The importance of sea ice loss both as an indicator and as an active player in the ongoing climate change has motivated some intense research into understanding the temporal evolution of sea ice on time scales from seasons to decades. In this contribution, I use a combined analysis of the observational record and of climate model simulations to explain and summarize some of these findings.

\section{Seasonal variability: The importance of atmospheric chaos}

Recent years have seen an increase in research activities aimed at forecasting the evolution of Arctic sea ice on time scales of a few months. There is good reason to believe that such seasonal-scale forecasts should be possible, with model studies emphasizing in particular the rather long memory of the sea ice state imprinted in the sea ice thickness fields (e.g., Blanchard-Wrigglesworth et al., 2011), and the long memory of the oceanic heat content that determines the regional evolution of Arctic sea ice (e.g., Bushuk et al., 2015).

The underlying research is in part driven by very practical applications, such as ship routing, but will also increase our fundamental understanding of air-ice-sea interactions at high latitudes. Related activities are for example coordinated by the Polar Prediction Project with its flagship Year of Polar Prediction 2017-2019 (www.polarprediction.net, under the auspices of WMO World Weather Research Programm WWRP), by the Polar Climate Predictability Initiative (www.climatecryosphere.org/wcrp/pcpi, under the auspices of the WMO World Climate Research Program WCRP), and by the Sea ice Prediction Network with its Sea ice Outlook activity (www.arcus.org/sipn).

In this latter activity, various research groups try to forecast the minimum Arctic sea ice area coverage in September based on the observed state of the sea ice cover from May onwards. The groups use a variety of methods, ranging from heuristic methods to seasonal prediction systems based on coupled climate models. An analysis of the forecast quality of the various methods has shown a mixed picture, with no single method giving significantly better results than any other (Stroeve et al., 2014).

This finding is possibly surprising in that idealised studies with seasonal prediction systems usually result in significant prediction skill of many months up to a few years in advance (Blanchard-Wrigglesworth et al., 2016). In this framework referred to as "perfect model", a single model simulation is taken as the "observed truth", while additional model simulations with slightly perturbed initial conditions are used to estimate whether this "truth" can be forecast.

The striking difference in the forecast quality of such idealised studies compared to those trying to forecast the real world might be explicable by three main factors. First, the forecast skill strongly depends on a proper knowledge of the initial state of the system. As shown by Bunzel et al. (2016), the incomplete knowledge of May sea ice concentration as reflected by the differences between different satellite data sets can cause differences 

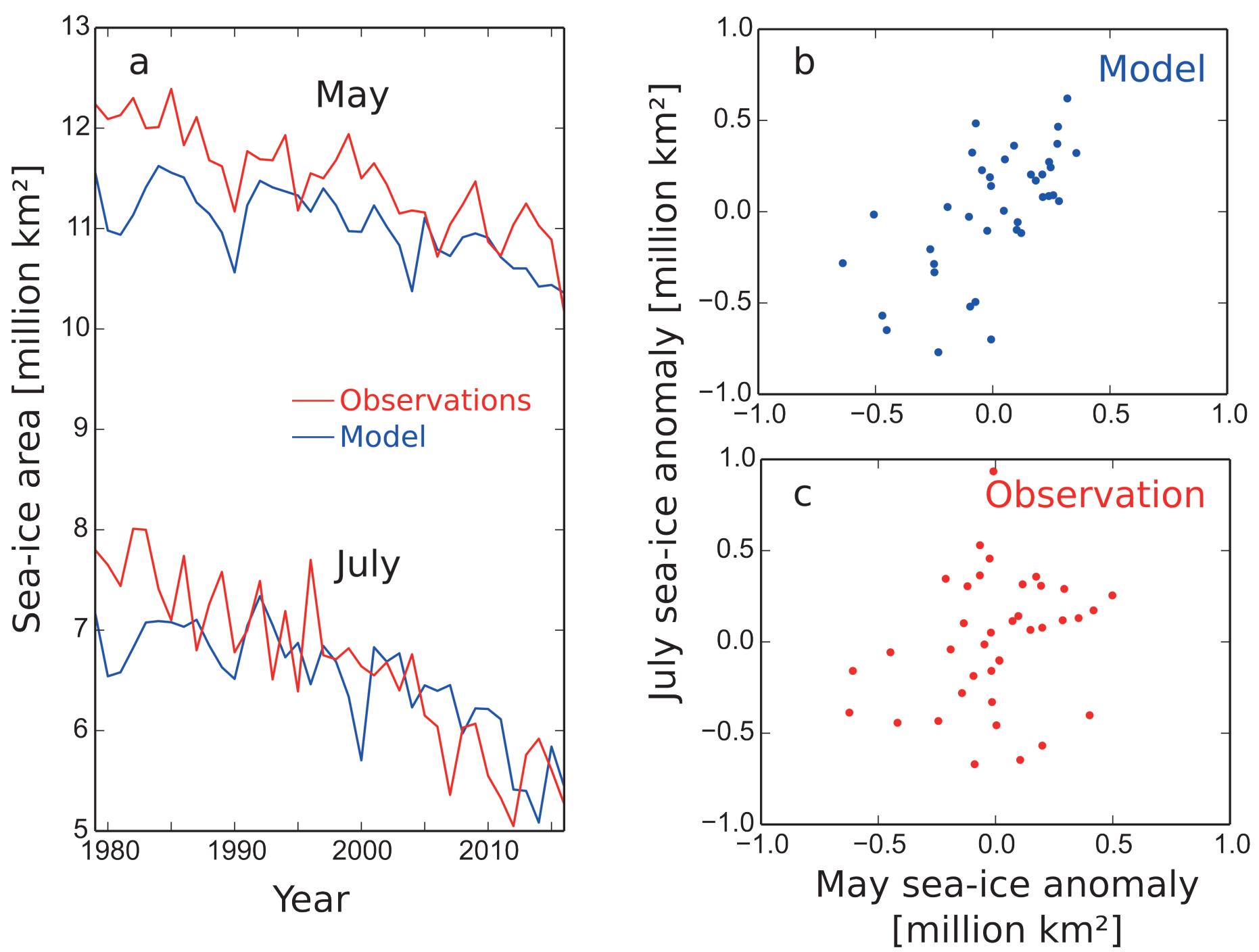

Figure 1: (a) Evolution of modeled and observed Arctic sea ice area in May and July (1979-2016). (b) Modeled Arctic sea ice area in July as a function of observed Arctic sea ice area in May of the same year. (c) Observed Arctic sea ice area in July as a function of observed Arctic sea ice area in May of the same year. Observations for all panels are based on the Arctic sea ice index (Fetterer et al., 2002, updated 2016). Model simulations for all panels are based on the first ensemble member of the CMIP5 simulations of MPI-ESM-LR (Notz et al., 2013).

in forecast mean September Arctic temperature of several degrees, and in forecast September Arctic sea ice area of 2 million $\mathrm{km}^{2}$. The incomplete knowledge of initial conditions of the sea ice cover arises because the microwave signature that is usually used to assess ice concentration reacts sensitively to snow coverage and melt-pond formation on the ice, for example. Different algorithms compensate these uncertainties in different ways, causing substantial differences of the observed sea ice area. Because of positive feedbacks such as the ice-albedo feedback, these differences in initial conditions are substantially amplified during summer and contribute to the much lower forecast quality of realworld applications compared to perfect model studies. Incomplete knowledge of the state of the underlying ocean certainly also contributes to these uncertainties.

Second, the forecast skill might be negatively affected by the initial shock and drift in the forecast runs in a real- world application. Both are absent in a perfect-model study, as its forecasts are usually started from a model state that is perfectly consistent with model physics. In contrast, the initial state for any simulation starting from a model state based on observations will usually be more or less inconsistent with model physics, possibly causing substantial drift that can quickly compensate for any added value from the assimilation of observations.

A third factor that might cause the systematically better forecast skill in idealised model studies relates to possible model errors in the simulation of the persistence of the Arctic sea ice cover. Take, for example, the relationship between Arctic sea ice area in May and Arctic sea ice area in July during the observational period 1979-2016 (Fig. 1a). The time series of these two months are highly correlated because of their underlying trend, both in the observations and in the model simulations. 
However, the detrended time series are only significantly correlated in the model simulations (Fig. 1b), with the Pearson rank coefficient of the correlations indicating a chance of far less than $1 \%$ that these time series are uncorrelated. In contrast, chances are above $30 \%$ that there is no significant correlation between the detrended observed time series of sea ice area in May and the detrended observed time series of sea ice area in July (Fig. 1c).

This suggests that at least an idealised study based on the particular model employed here (MPI-ESM-LR) will result in an unrealistically large potential forecast skill of seasonal predictions. We are currently examining whether this finding also holds for other models, and are in particular trying to investigate the underlying reasons for this different behaviour in the model compared to reality.

\section{Annual variability: The importance of negative feedbacks}

In addition to seasonal forecasts on time scales of a few months, also forecasts on time scales of a few years have made some headlines over the past decade. These headlines were usually related to claims that the Arctic would lose its remaining summer sea ice within just a few years. The underlying reasoning of such claims was often related to a discussion of a possible 'tipping point' that is related to the ice-albedo feedback. Given the substantial loss of Arctic sea ice in the past few years, the ocean could potentially absorb enough heat to rapidly melt the remainder of the sea ice cover.

However, our current understanding of the Arctic climate system strongly suggests that this reasoning is unrealistic. A first indication for this finding derived from model experiments in which all Arctic sea ice was synthetically removed from the Arctic Ocean at the onset of summer, thus maximising the possible ice-albedo feedback (Tietsche et al., 2011). Despite such maximised feedback, the ice cover recovered in these experiments within just a few years. This is because on annual time scales, negative feedbacks dominate the evolution of the Arctic sea ice cover. Three negative feedbacks are particularly important: First, the open ocean very effectively releases its heat to the atmosphere during winter, causing a rapid loss of much of the heat that was accumulated in the icefree water during summer. Second, the thin ice that forms during winter can grow much more rapidly than ice that survived the summer, because heat can more effectively be transported from the ocean to the atmosphere when the ice cover is thin (Bitz and Roe, 2004). Third, as ice forms later in the season, it will carry a thinner insolating snow cover as any snow fall occurring before ice formation simply falls into the open ocean (Notz, 2009).

The effectiveness of these negative feedbacks on an annual time scale is not only apparent in our model simulations; a) September sea-ice area

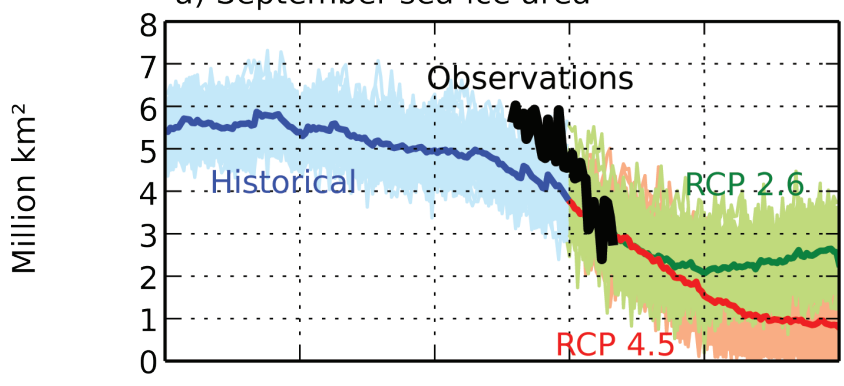

b) 10 year trend
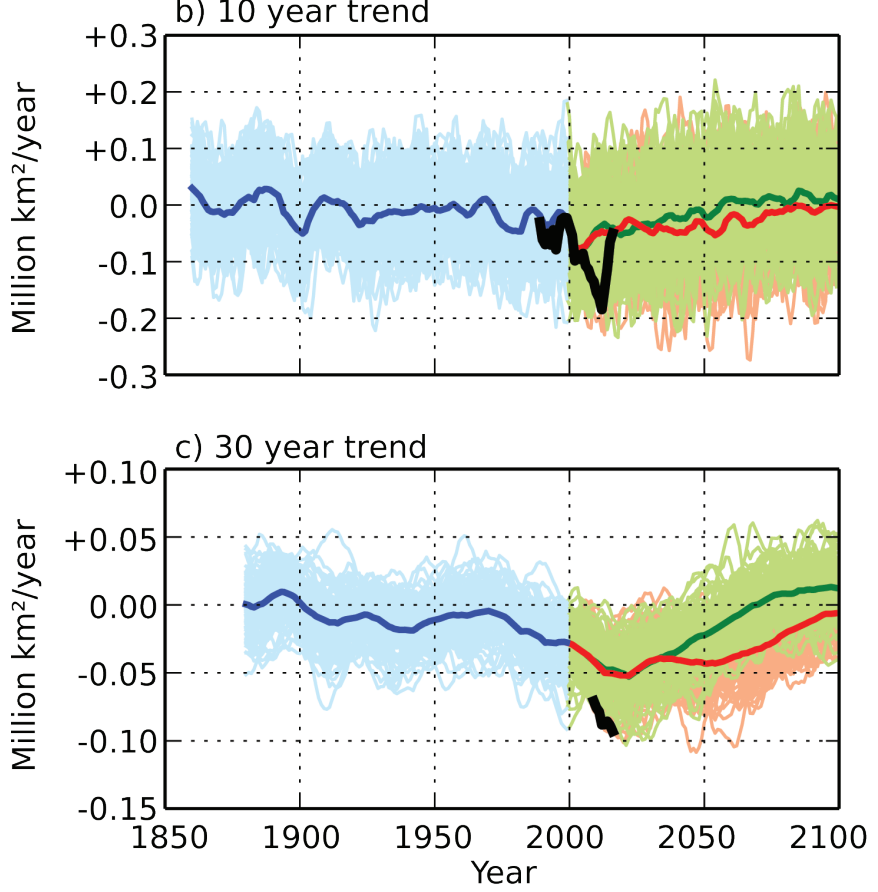

d) September sea-ice area

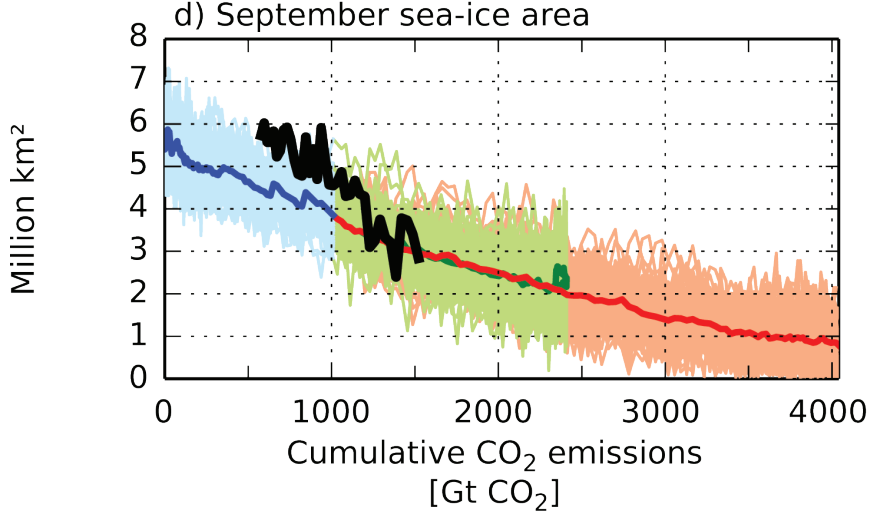

Figure 2: (a) Evolution of modeled and observed Arctic sea ice area in September (1850-2016). (b) Evolution of ten-year linear trends of Arctic sea ice area, plotted at the end point of the ten year averaging period. (c) Evolution of thirty-year linear trends of Arctic sea ice area, plotted at the end point of the thirty year averaging period. (d) Evolution of modeled and observed Arctic sea ice area in September (1850-2100) as a function of cumulative anthropogenic $\mathrm{CO}_{2}$ emissions. Observations for all panels are based on the Arctic sea ice index (Fetterer et al., 2002, updated 2016). Model simulations for all panels are based on the 100 member ensemble of MPIESM-LR. 
the observed time series of Arctic summer sea ice also carries a clear signature of such mechanisms. A year with a strong drop in ice coverage during September is usually followed by an increase in September ice coverage in the following year. More formally, the time series shows significant negative autocorrelation (Notz and Marotzke, 2012). If indeed the ice albedo feedback was as effective on annual time scales as implied by statements supporting the entire loss of Arctic summer sea ice within this decade, one would certainly expect that any year with a strong drop in ice coverage would be followed by a year with yet another drop. This is found neither in the observational record, nor in model simulation. This underpins the dominance of negative feedbacks, which stabilize the Arctic ice cover and prevent a possible "tipping point".

\section{Decadal variability: The importance of internal variability}

Internal climate variability not only governs a substantial part of the sea ice evolution on seasonal-to-interannual time scales as discussed above, but also affects the longer term trends of sea ice (Swart et al., 2015; Notz, 2015). To exemplify this, large ensembles of simulations of coupled Earth System Models are particularly helpful (Swart et al., 2015). At the Max-Planck-Institute for Meteorolgy, we have recently finished a 100 member large ensemble of simulations with our Earth System Model MPI-ESMLR for the historical period, and for two possible future emission scenarios, RCP2.6 and RCP4.5. In comparing the simulated Area sea ice area during September with the observational record 1979-2016, we find that the observed sea ice area is at the upper edge of the ensemble spread during the earlier years of the record, and approaches the mean of the ensemble in the more recent past (Fig. 2a).

Ten-year long trends within the observational record have consistenly been negative with values ranging from a mean loss of $23000 \mathrm{~km}^{2}$ per year during the period 1990-1999 to a mean loss of $180000 \mathrm{~km}^{2}$ during the period 2003-2012 (black line in Fig. 2b). This latter period includes the two record minima that have been observed in 2007 and 2012. For the most recent period 2007-2016, the average ice loss has been around $50000 \mathrm{~km}^{2}$ per year. All these numbers are well within the range simulated by individual ensemble members of MPI-ESM-LR, which show over ten year-long periods a sea ice evolution ranging from a mean loss of around $200000 \mathrm{~km}^{2}$ per year to a mean gain of around $100000 \mathrm{~km}^{2}$ per year (shaded range in Fig. 2b). In particular, it is noteworthy that the mean ten-year long trends for the first 20 years of the satellite record and for the most recent past are very close to the mean trend of the 100 member ensemble, including a slowdown of the ice loss during the 1990s and an accelaration during the early 2000s. This agreement during substantial periods of the record suggests that the rather sudden drop in observed sea ice area that occured in the year 2007 has been an extreme event compatible with internal climate variability and therefore cannot directly be compared to the ensemble mean across several models or to the ensemble mean across multiple simulations with one model. If this characterisation of this sea ice loss as an extreme event was correct, any realistic climate model should on average simulate a slower ice loss than has been observed (see also Notz (2015) for a detailed discussion).

Regarding the future evolution of sea ice, the model simulations with MPI-ESM-LR suggest a similar range of possible ten year trends than over the past few decades. Hence, in extreme cases and providing the hypothesis that the level of internal climate variability simulated is correct, the sea ice cover might in the future potentially once again lose ice as fast as during the first decade of this century, or, in contrast, gain an average of 100000 $\mathrm{km}^{2}$ per year for a decade despite the ongoing global warming (see also Swart et al., 2015).

In order to more confidently predict the near-term evolution of Arctic sea ice, the underlying reasons for internal variability must be understood better. A number of recent studies point in particular to the impact of oceanic heat transport into the Arctic for driving lowfrequency variability of the ice cover, including a possible contribution to the recent acceleration of sea ice loss (e.g., Årthun et al., 2012). These studies emphasize that a scenario with a much slower sea ice loss for the next decade is plausible if oceanic heat transport were to weaken (Zhang, 2015; Yeager et al., 2015). Such weakening of the oceanic heat transport would not only affect the sea ice cover itself, but also its future predictability on seasonal time scales (Germe et al., 2014). This then directly links the challenge of decadal forecasting of sea ice to that of its seasonal forecasting as described in the previous section.

\section{Long-term changes: The importance of the external forcing}

On longer time scales, internal variabililty also remains a substantial contributor to the evolution of Arctic sea ice area. The 100 member simulations suggest a possible spread in observed September sea ice area of around 2 million $\mathrm{km}^{2}$ for any given year (Fig. $2 \mathrm{a}$ ). In terms of trends, even long-term trends over 30 years show substantial variability (Fig. 2c). For example, the model suggests that over the past 30 years, sea ice area in the Arctic could have remained roughly constant or could have decreased roughly as quickly as observed. This large spread in 30year long trends again suggests that using these trends as metrics for the purpose of model evaluation can be misleading (Notz, 2015), in particular if the observed evolution of Arctic sea ice corresponds to a possible extreme event. 
Despite the large impact of internal variability, the dominant role of external forcing in the observed evolution of Arctic sea ice is clear (Notz and Marotzke, 2012). The weight of the external forcing becomes particularly apparent if one examines the average evolution of Arctic sea ice coverage in the 100 member ensemble as a function of cumulative anthropogenic $\mathrm{CO}_{2}$ emissions (Fig. 2d). The long-term evolution of the sea ice cover directly follows the cumulative emissions. In particular, there is no clear difference in mean sea ice coverage between RCP 2.6 and RCP 4.5 for any given cumulative $\mathrm{CO}_{2}$ emission.

We have recently been able to explain this relationship, which is largely based on the fact that the position of the outer edge of the sea ice cover is determined by the net local energy balance (Notz and Stroeve, 2016). Any rise in atmospheric $\mathrm{CO}_{2}$ concentration increases the incoming longwave radiation at the ice edge, causing the latter to move northward to a region with less incoming shortwave radiation. For geometric reasons, these combined processes lead to a roughly linear relationship between Arctic sea ice loss and anthropogenic $\mathrm{CO}_{2}$ emissions in the obervational record and in all CMIP5 model simulations. In the obervations, about $3 \mathrm{~m}^{2}$ of sea ice are lost per ton of $\mathrm{CO}_{2}$ emissions, while the models on average only simulate an ice loss of $1.7 \mathrm{~m}^{2}$ per ton of $\mathrm{CO}_{2}$ emissions.

The fact that the relationship between cumulative $\mathrm{CO}_{2}$ emissions and Arctic sea ice area is roughly linear strongly suggests a dominating role of the $\mathrm{CO}_{2}$ emissions for the evolution of sea ice area. However, other external drivers are also apparent, in particular in the mean across all simulations of our 100-member ensemble. Most striking are temporary increases in Arctic sea ice area following large volcanic eruptions during the historical period, most recently in 1991 after the Pinatubo eruption, in 1982 after the eruption of El Chichon and in 1963 after the eruption of Mount Agung (compare also Zanchettin et al., 2014). Because of the large internal variability and the relatively short-lived response, these eruptions are impossible to identify in the temporal evolution of individual simulations nor the observational record, but they apparently have contributed to a synthetic improvement of CMIP5 sea ice simulations relative to CMIP3 sea ice simulations (Rosenblum and Eisenman, 2016).

\section{Conclusions}

This short overview presents some recent work on the variability and long-term evolution of Arctic sea ice area. For space constraints, the focus was only on September sea ice coverage as this is the month with the strongest observed trends. The discussion can be summarized as follows:

- On seasonal time scales, atmospheric internal variability and its imprint on sea ice renders skillful predictions of September sea ice coverage more than two months in advance inherently difficult.

- On annual time scales, negative feedbacks stabilize the sea ice cover. There is no "tipping point" beyond which the loss of the remaining summer sea ice becomes unstoppable

- On decadal time scales, internal climate variability can cause a substantial acceleration or temporary recovery of the sea ice cover that renders the evaluation of individual model simulations based on their short-term trends impossible.

- On longer time scales, internal variability causes a substantial spread in possible 30-year long trends supporting for the production of large model ensembles. Nevertheless, the impact of anthropognic forcing on the long-term sea ice evolution is clear, with an average loss of $3 \mathrm{~m}^{2}$ of September sea ice cover per metric ton of anthropogenic $\mathrm{CO}_{2}$ emission.

\section{References}

Årthun, M., T. Eldevik, L. H. Smedsrud, Ø. Skagseth, and R. B. Ingvaldsen, 2012: Quantifying the influence of Atlantic heat on Barents Sea ice variability and retreat, J. Clim., 25, 4736-4743, doi:10.1175/JCLI-D-11-00466.1.

Bitz, C., and G. Roe, 2004: A mechanism for the high rate of sea ice thinning in the Arctic Ocean. J. Clim., 17 (18), 3623-3632.

Blanchard-Wrigglesworth, E., K. C. Armour, C. M. Bitz, and E. DeWeaver, 2011: Persistence and inherent predictability of Arctic sea ice in a GCM ensemble and observations, J. Climate, 24, 231-250.

Blanchard-Wrigglesworth, E., and Coauthors, 2016: Multi-model seasonal forecast of Arctic sea ice: forecast uncertainty at pan-Arctic and regional scales. Clim. Dyn., 1-12, 10.1007/s00382-016-3388-9.

Bushuk, M., D. Giannakis, and A. J. Majda, 2015: Arctic sea ice reemergence: The role of large-scale oceanic and atmospheric variability, J. Climate, 28, 5477-5509.

Bunzel, F., D. Notz, J. Baehr, W. A. Müller, and K. Fröhlich, 2016: Seasonal climate forecasts significantly affected by observational uncertainty of Arctic sea ice concentration. Geophys. Res. Lett., 43 (2), 2015GL066 928, 10.1002/2015GL066928.

Fetterer, F., K. Knowles, W. Meier, and M. Savoie, 2002, updated 2016: Sea ice index. Digital media, National Snow and Ice Data Center, Boulder, Colorado USA.

Germe, A., M. Chevallier, D. S. y Mélia, E. Sanchez Gomez, and C. Cassou,2014, Interannual predictability of Arctic sea ice in a global climate model: Regional contrasts and temporal evolution, Clim. Dyn., 43(9-10), 2519-2538.

Notz, D., 2009: The future of ice sheets and sea ice: 
Between reversible retreat and unstoppable loss. Proc. Nat. Ac. Sci., 106 (49), 20 590-20 595, doi:10.1073/ pnas.0902356 106.

Notz, D., 2015: How well must climate models agree with observations? Phil. Trans. R. Soc. A, 373 (2052), 20140 164, 10.1098/rsta.2014.0164.

Notz, D., A. Haumann, H. Haak, J. Jungclaus, and J. Marotzke, 2013: Arctic sea ice evolution as modeled by MPI-ESM. J. Adv. Model. Earth Syst., 5, 173-194, 10.1002/ jame.20016.

Notz, D., and J. Marotzke, 2012: Observations reveal external driver for arctic sea ice retreat. Geophys. Res. Lett., 39 (8), L051 094, 10.1029/2012GL051094.

Notz, D., and J. Stroeve, 2016: Observed Arctic sea ice loss directly follows anthropogenic $\mathrm{CO}_{2}$ emission. Science, aag2345, 10.1126/science.aag2345.

Pithan, F., B. Medeiros, and T. Mauritsen, 2013: Mixedphase clouds cause climate model biases in Arctic wintertime temperature inversions. Clim Dyn, 43 (1-2), 289-303, 10.1007/s00382-013-1964-9.

Rosenblum, E., and I. Eisenman, 2016: Faster Arctic Sea ice Retreat in CMIP5 than in CMIP3 due to Volcanoes. J. Climate, 29 (24), 9179-9188, 10.1175/JCLI-D-16-0391.1.

Stroeve, J., L. C. Hamilton, C. M. Bitz, and E. BlanchardWrigglesworth, 2014: Predicting September sea ice: Ensemble skill of the SEARCH Sea ice Outlook 20082013. Geophys. Res. Lett., 41 (7), 2014 GL059 388, 10.1002/2014GL059388.

Swart, N. C., J. C. Fyfe, E. Hawkins, J. E. Kay, and A. Jahn, 2015: Influence of internal variability on Arctic sea ice trends. Nature Clim. Change, 5 (2), 86-89, 10.1038/ nclimate2483.

Tietsche, S., D. Notz, J. H. Jungclaus, and J. Marotzke, 2011: Recovery mechanisms of Arctic summer sea ice. Geophys. Res. Lett., 38 (L02707), 10.1029/2010GL045698.

Yeager, S. G., A. R. Karspeck, and G. Danabasoglu, 2015: Predicted slowdown in the rate of Atlantic sea ice loss, Geophys. Res. Lett., 42, doi:10.1002/2015GL065364.

Zanchettin, D., O. Bothe, C. Timmreck, J. Bader, A. Beitsch, H. F. Graf, D. Notz, and J. H. Jungclaus, 2014: Inter-hemispheric asymmetry in the sea ice response to volcanic forcing simulated by MPI-ESM (COSMOS-Mill). Earth Syst. Dynam., 5, 223-242.

Zhang, R., 2015: Mechanisms for low-frequency variability of summer Arctic sea ice extent, Proc. Natl. Acad. Sci. 